\title{
Race 2050: trends in the demand for transportation systems
}

\author{
M. Silva, N. Ribeiro \& M. Rodrigues \\ VTM Consultores de Engenharia, Portugal
}

\begin{abstract}
This paper aims to present the results of an assessment of the crucial driving forces and demand challenges that the European transport industry faces, raising awareness for the demand-side driving forces influencing transport systems development and foreseeing its evolution, highlighting the major factors structuring world demand for transport equipment, infrastructure and supporting systems up to 2030 and beyond, such as GDP evolution, Ageing, Urbanization Growth, Environmental Challenges, Energy, Congestion, etc., are discussed with a particular focus on future urban mobility requirements. This paper highlights the main conclusions on future demand for transport systems, developed in the course of EU funded Research Project RACE 2050 'Responsible innovation Agenda for Competitive European transport industries up to 2050'.
\end{abstract}

Keywords: transportation demand, driving forces, European transport industry.

\section{Introduction}

The European Research Project RACE 2050 - 'Responsible innovation Agenda for Competitive European transport industries up to 2050' - funded by the European Union's Seventh Framework Programme (FP7/2007-2013) under grant agreement no. 314753 - aims at identifying key success factors for a climate and environment friendly and socially acceptable growth of the European transport industry, in a long term perspective up to 2050.

The present strength of the European transport industry is to a large extent the fruit of preparedness for change and of having learned from sometimes dramatic transport foresight studies and threat scenarios and to follow convincing positive visions. 
RACE 2050's main goal is to come forward with novel scenarios for 2030 and 2050 on the future competitiveness of the European transport industry. Important drivers of change were extracted by integrating the tremendous available foresight intelligence and analyzing current policies, emerging technologies, energy and environment aspects, demand forces, geopolitical trends and other relevant domains.

The present paper presents the main findings and conclusions regarding the expected evolution of demand trends and challenges for the transportation industry, with a particular focus on urban transport systems.

\section{Current demand driving forces}

Transport is usually described as a 'derived demand' in the sense that demand for transport is almost always determined by broader aspects of economic or personal activity [1]. Freight must be moved from production point to markets, and passengers travel to work or to shop or for leisure: rarely is the trip itself the object of the transport, except maybe for tourism or sporting events. Transport thus has been understood to arise from other drivers rather than being a principal actor. The most influential societal and economic driving forces for future personal transportation demand patterns are highlighted and referenced in this chapter.

Beyond individual mobility needs, the population size, density, structure and expected growth rates are among the most important parameters that help to explain trip generation, mode choices and infrastructure use. The following sections highlight the major challenges that cities face in the near future.

\subsection{Population prospects}

According to the United Nations [2], the current world population of 7.2 billion $\left(10^{9}\right)$ is projected to increase by almost a billion up to 2025 , and further increase to 9.6 billion in 2050 and reach 10.9 billion in 2100 .

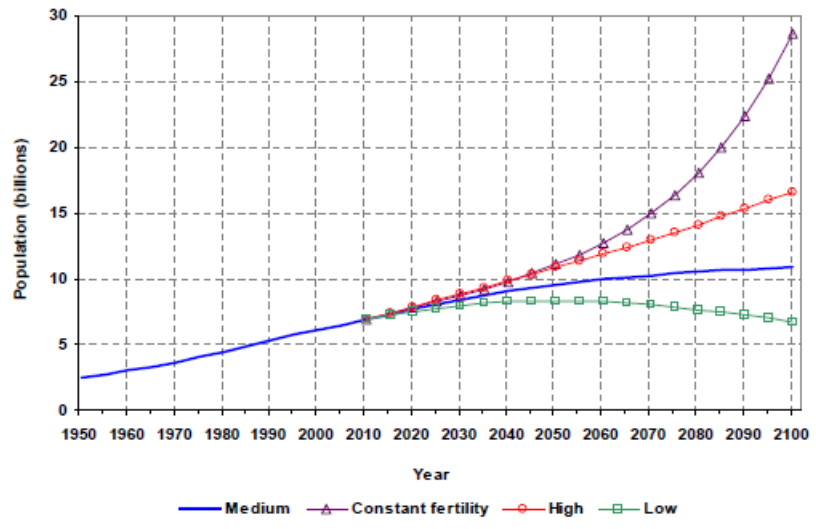

Figure 1: Population of the world, 1950-2100, according to different projections and variants (DESA - UN 2013). 
Almost all of the additional people will enlarge the population of developing countries, which is projected to rise from nowadays' 5.9 billion to 8.2 billion in 2050, and will mainly be distributed among the population aged 15 years and over, while the number of under 15 will hardly increase.

Growth is expected to be particularly dramatic in the less developed countries, which are projected to double in size from 898 million inhabitants in 2013 to 1.8 billion in 2050 .

In contrast, the more developed regions will see its population growing modestly or even declining, with its total population passing from 1.25 billion in 2013 to 1.28 billion in 2100 , supported by migration from developing to developed countries, projected to average about 2.4 million persons annually to 2050 .

India is expected to overtake China in total population by 2030 , becoming the largest country in total population, with over 1.5 billion inhabitant against China's 1.4 billion, while Europe will surpass the 515 million, followed by the USA with 360 million, Indonesia (280 million), Nigeria (258 million), Pakistan (234 million) and Brazil (220 million).

Economic and demographic asymmetries across countries are likely to remain powerful generators of international migration, with the main origins projected to be Bangladesh $(-331,000)$, China $(-300,000)$, India $(-284,000)$, México $(-210,000)$, Pakistan $(-170,000)$, Indonesia $(-140,000)$ and Philippines $(-92,500)$, and the major net receivers the USA $(1,000,000)$, Canada $(205,000)$, UK (175,000), Australia (131,250), Italy (131,250), Russian Fed. (127,500), France $(106,250)$, and Spain $(102,500)$ [2].

\subsection{Ageing}

Population ageing is one of the most significant global trends of the 21 st century. In 1950, there were 205 million persons aged 60 or over. By 2012 this number increased to 810 million, and it is projected to grow to 1 billion in less than 10 years and double by 2050, reaching 2 billion [3]. By then there will be more people aged 60 or over than children under 15. In China, this will happen in less than 10 years.

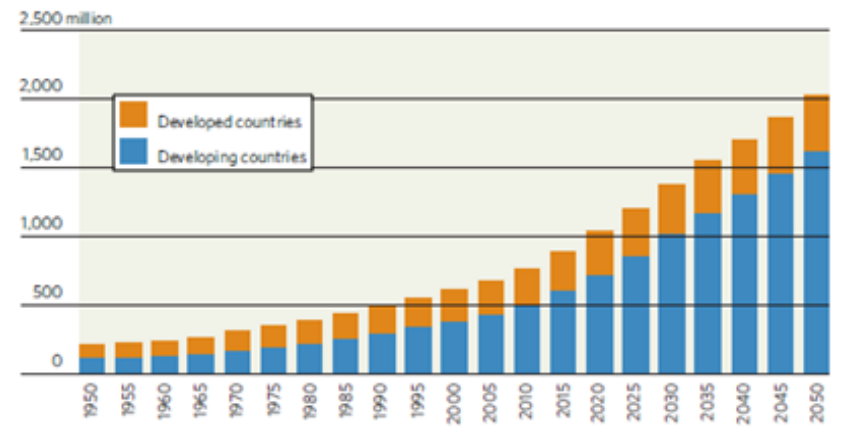

Figure 2: $\quad$ Number of people in the world aged 60 of over (UNFPA 2012). 
Europe today has the oldest population, with a median age of 41 years, which is expected to reach 46 years in 2050. Globally, the median age is projected to increase from 29 to 36 years between 2013 and 2050. This is increasingly a globalized phenomenon - Japan is nowadays the only country with more than $30 \%$ of its population aged 60 or over, but by 2050 there will be over 60 countries in the same situation. By then, nearly four in five people aged 60 or over will live in the developing world [3].

Increasing longevity - due to improved nutrition and health care, sanitation, medical advances and economic well-being leading to increasing survival and declining fertility rates - is one of mankind's greatest achievements. Yet, this raises significant concerns on future society's capability to address the associated challenges. Globally, only one-third of countries, covering just $28 \%$ of global population, have comprehensive social protection schemes.

On the other hand, the ageing population is a source of great opportunities for society and businesses if managed correctly. An age-friendly environment that promotes active ageing, supported by innovative technologies, is especially important as people grow older and experience reduced mobility and other impairments. Easily accessible transportation is essential to maintain independence, facilitate social contacts and enable oldsters to remain active in society.

\subsection{Gross domestic product (GDP), income growth and distribution}

From 2000 to 2010, the world's economic centre of gravity has shifted further than at any time (see Figure 4), moving eastwards after years moving west due to the profound productivity gains and mass urbanization that came during the British and America Industrial Revolutions [4].

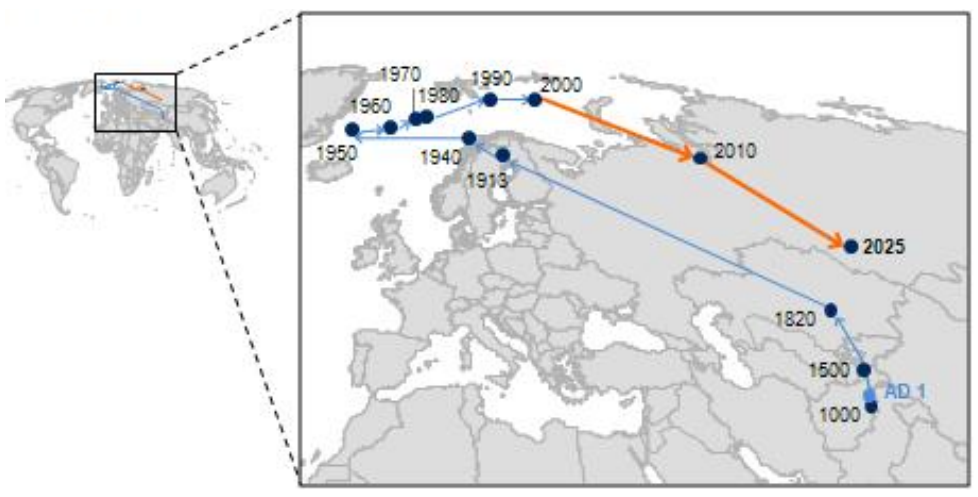

Figure 3: Evolution of the earth's economic centre of gravity (from A.D.1 to 2025) [4].

This eastward movement has been mainly explained by a number of rapidly growing mid-to-large sized metropolitan areas in Asia - their productivity growth is elevating millions of poor to the ranks of the consumer class. China alone has 
242 cities - 236 of them are middleweights - in the City 600, a group constituted of 600 cities which is predicted to generate $65 \%$ of world economic growth by 2025. India is another Asian country where the increasing size and power of their cities will be translated into rising incomes and, consequently, a rapid growth demand for many goods and services.

Global real GDP is expected to increase over the next 30 years by 2-3 times [5], with the largest percentage growth in per capita GDP taking place in the medium or low-income countries, particularly China, India, Vietnam and Indonesia.

By 2050, China, the USA and India are likely to be by far the three largest economies in the world. As well as the rise in China and India already noted, another notable development projected is that Mexico and Indonesia could rise to be amongst the top 10 largest economies - ranking 7 th and 8 th respectively by 2050 in terms of GDP at PPPs.

An increase in GDP and in personnel income, at worldwide level, translates into an increase of people's propensity to travel more frequently, further, faster and more comfortably, as it affects the level of consumer purchasing power, the propensity of consumers to undertake leisure travel and valuing more quality and comfort while travelling.

In China and India, the most populated countries in the world, the majority of households do not yet have a car; however, these countries are reaching the stage of development where a rapid take off in car ownership and in mobility in general may be expected. Current motorization levels in emerging economies (e.g. 37 passenger cars for 1000 inhabitants in China, 16 in India or 150 in Brazil) combined with rising middle classes and household incomes or increasing population in working age (India), are giving support to an ever rising world private car fleet.

Accordingly, worldwide car sales are reaching record levels due to the development of emerging economies and it is expected that they will continue to grow. Total automotive sales are expected to grow from 78 million in 2012 to more than 100 million by 2020 . Asia's the unquestionable leader of the market, with half the percentage of global production volume and $44 \%$ of global sales volume.

China is nowadays the biggest market in terms of sales, despite the increasing limitations on new licence plate registration or car use restrictions on major cities, with more than 13 million passenger cars sold in 2012, against only 2 million sales in 2000 [6], adding to a fleet of over 93 million cars by 2013. This increase in private car ownership and ridership is hardly balanced by capacity improvements and is leading urban systems to gridlock - ${ }^{\prime} 80 \%$ of the roads and $90 \%$ of the junctions have almost reached capacity limit in urban Chinese cities with $>1$ million inhabitants' [7], and poor living standards (pollution, congestion, safety).

Economic growth has lifted millions from poverty, but several economic risks lie on the horizon, mostly from fiscal crisis and youth unemployment in key economies. While prospects for the young generations are brighter in high-growth markets, particularly in Asia, where the middle classes are rising, the youth unemployment rates and precarious jobs situations have soared in developed 
economies since the 2008 crisis leading to references to a 'lost generation', while middle classes are increasingly under pressure from growing global competition and face declining living standards, as at the same time income inequities rises.

\subsection{Urbanization patterns}

Urbanization stands for the increase in the urban share of total population. Cities hold important scale and proximity benefits - they generate jobs and income in larger numbers, provide education and health care. In a world battered by growing income disparities, cities can help promote equity in important domains of society, by making public interests prevail in urban areas - as equity is one of the main drivers of happiness [8]. Quality public spaces and transport systems are the cornerstone of 'quality of live equality', as they constitute the only places where all citizens meet as equals in cities.

The world's urban population grew from 220 million to 2.8 billion over the 20th century. In 2008, the world's population living in urban areas surpassed the rural population for the first time.

While the urban population in the developed world is expected to grow marginally between 2000 and 2030, from 810 to 1 billion urbanites, the next decades will witness an unprecedented scale of urban growth in the developing world, particularly in Asia and Africa, where urban population is expected to double until 2030 [9] - from 1.36 billion to 2.64 billion in Asia, and from 294 million to 742 million in Africa. China has been and will remain the main force driving global urbanisation, as the projected number of urban residents in the country will increase by 268 million between 2010 and 2030 [10].

According to Roland Berger [11], the developed countries' share of urban population will increase by $5.7 \%$ to $81 \%$ while developing urban population share will increase by $9.9 \%$ to $55 \%$, in 2030 . Developing countries will account, as a whole, for $80 \%$ of world's urban population.

The main cause for future urbanization will be natural increase, responsible for some $60 \%$ of expected growth, while land requalification and migration will share the remaining $40 \%$. Peri-urbanization and corridorization is transforming rural settlements into urban ones without displacing most of their residents and is home to a variety of economic activities, although it lacks some economic advantages of agglomeration.

It is now assumed that half the urban population increase is likely to take place in smaller cities and towns (500,000 to 1 million inhabitants), with weaker capabilities for planning and implementation of the infrastructural requirements that the expected evolution calls for. Developing countries' cities should already be making serious plans for urban expansion and planning infrastructures to accommodate the projected expansions, with a key concern on the poor - as present urban problems are only the tip of the iceberg that lies ahead. Indeed, although the large increase in wealth and middle-class figures in developing countries, urban population growth in the 21 st century will be composed, to a large extent, of poor people [12].

While urbanization provides important economic and social gains, it substantially increases risks related to ecological disruptions, pollution, climate 
change and environmental adversities [13]. Urbanization has global and local environmental impacts, for example, in the form of greenhouse gases and resource use, as more and more steel and energy is required to build them, but they hold inherently the potential value to long-term sustainability, as the potential benefits of urbanization and human concentration far outweigh the disadvantages, giving sustainability a better chance.

From the transport perspective, compact and densely populated areas are a requirement for improved public transport services, which then again leads to an increased use of public transport [14]. A combination of urban planning, good public transport services and improved infrastructure for active modes is needed to reduce the land area used for transport infrastructure and to make the land use more efficient [15]. A reduced need for travel and for private transportation could be achieved through urban planning, which then again would reduce congestion in urban areas and emissions caused by the transport sector $[15,16]$. Developing efficient liveable cities is seen as a means of moderating potential social unrest, with potential yearly savings of 2,000 vkm per person resulting from shorter average journeys as well as a shift to public transport and two-wheelers.

\subsection{Changing lifestyles and mobility behaviours}

Settlement patterns are influenced by urbanisation as well as lifestyle changes, as influencing factors such as income, transport infrastructure and regional economic situations are changing. In the last decades many countries' infrastructural development has been influenced by auto mobilization, enabling the combination of individual housing preferences with job opportunities [15].

Society has changed fundamentally over the last decades, affecting demand for transportation. The size and spatial distribution of households changes the demand for living space and settlement patterns. Due to smaller household size, more complex mobility is needed to establish and maintain social contacts as well as to conduct other activities, which then again increase the demand for transportation [17].

Increased connectivity is also changing the way people work, socialize and interact with their surroundings. Innovation such as the Internet and mobile phone have boosted productivity, created new business opportunities and enhanced access to information. Smart phones increasingly make it possible for individuals to move around and get access to whatever services they need whenever or wherever they need them. Flexible working hours, home office and online services will expectedly change urban mobility dynamics in the future.

Social responsibility and ecological sustainability are increasingly crucial topics throughout the world, as consumers look increasingly for the products that have a minimal impact on the environment. Sustainability is not only about being green, but also durable. As social values and behavioural patterns evolve, purchasing patterns will move towards more conscious consumption. Consumers increasingly prefer to share certain items with each other rather than own them.

We witness a paradigm shift from ownership to usership based models, and the advent of a shared economy. Cars are particularly good for sharing as they are among the most expensive consumer goods, and most of the time they just sit idle 
[18]. Car sharing companies are booming in most developed markets - as membership of such clubs have risen from 1.3 million in 2010 to 3.3 million in 2013, and is expected to exponentially grow to around 26 million by 2020 [19]. According to Singh, over 40\% of Zipcar's members - one of the world's largest car sharing clubs - have given up ownership of their personal vehicles, and for each car that enters a car sharing scheme, about seven to nine cars are removed from streets.

Car sharing isn't the only game-changing urban mobility business model of the future, as they constitute just a portion of the dynamic and inter-modal integrated transport solutions - mobility integrators - that will make transportation easier in future cities, supported on new vehicles' technological concepts, new business models, inter-connectivity and inter-mobility. Some studies point out to considerable reductions in car fleets in the medium term, as cities become greener, pleasant places to live. Car ownership levels are peaking throughout the developed countries, as new generations of consumers give less and less importance to personal motorization.

Frugal products, simple, no-frills concepts with increased functionality, low technological incorporation and low cost are supporting the competitiveness of developing countries' industrial players, and affordability will increasingly be a key concept for all markets. For most companies in Western markets, innovation has meant the development of new products with more advanced features at premium prices. But companies will need to master the art of frugal innovation to compete in emerging markets.

\subsection{Environmental challenges}

Climate change is a global phenomenon caused by excessive greenhouse gas (GHG) emissions. It has a negative impact on the environment, economy and society, leads to extreme weather conditions and affects the land use negatively [20]. Besides indirect effects of global warming the extreme weather conditions, precipitation and changing temperatures have direct negative impacts and can cause damage to the transport infrastructures.

Transportation is responsible for $20 \%$ of all $\mathrm{CO}_{2}$ emissions, with road transport responsible for three-quarters [21]. Air pollution has a negative impact on local air quality and human health and is caused by traditional fuel burning engines [22]. The pollution is mainly in the form of particulate matter and chemicals such as nitrogen compounds and is especially a problem in metropolitan and urban areas [23].

Nowadays, the emissions of sulphur dioxides have already been significantly reduced due to legislative measures and technological changes [23].

In the future, major $\mathrm{CO}_{2}$ emission reductions in transport can be achieved through more efficient vehicles, a shift towards electricity and biofuels and progressive adoption of natural gas followed by a transition to biogas. The shift from private modes to public and active modes also supports the targets for declining emissions. 


\subsection{Energy sources and technological innovations}

The transportation sector is currently the second largest sector in energy consumption (second only to the industrial sector), responsible for consuming $30 \%$ of the world's energy production. The global transport sector consumed more than $60 \%$ of the oil in 2010 , as most energy for transportation is based on fossil fuels, and particularly fossil oil (97.6\%). Of all the energy that goes into transportation, road transport can account for around $80 \%$.

In 2010 the main energy sources in OECD countries and globally were oil and natural gas. Biofuels and RDF (refuse derived fuel) made up $12.7 \%$ of global energy use, but only $4.9 \%$ of OECD countries.

In OECD countries, oil had a share of $48 \%$ in 2010 and natural gas $20 \%$. Globally, the corresponding numbers were $41 \%$ and $15 \%$ [24]. It is assumed that the share of natural gas as an energy source will increase in the future and the proportion of oil will decrease [23].

According to Roland Berger [21], by 2025 automakers will be offering a wider range of drivetrain technologies to serve the different usage patterns arising from changes in mobility behaviours and new regulations, aiming at reducing emissions from transport, from the ever predominant gasoline/diesel, to natural gas, biofuels, electricity and even hydrogen, although viewed today much as a niche application. As a side note, some engine providers in aviation, such as Pratt and Whitney, already have all their engines certified to run with 50/50 blends of biofuels and jet fuel.

World production of unconventional liquid fuels is expected to increase from nearly 4 million barrels a day in 2008 to 13.1 million barrels a day in 2035, which should account for $12 \%$ of the total world liquid fuel supply. Of this amount, the largest component is expected to come from the Canadian oil sands (4.8 million barrels a day), and a lesser amount from US and Brazilian biofuels and Venezuelan extra-heavy oil.

As developed urban societies hopefully opt for the increased decarbonisation of transportation systems, conventional fuels will expectedly still be responsible for the majority of the markets, with its prices closely connected to the evolution of global wealth and trade.

\section{Congestion}

Congestion is a significant challenge of transport. Congestion occurs as a consequence of transport demand equalling or exceeding system capacity. It generates extra costs to the economy in terms of delays, time and resources wasted and increased fuel consumption and pollution. As transport networks and nodes (e.g. maritime ports and airports) run near capacity and more users enter the system, delays increase in a disproportional way, eventually leading to gridlock. This phenomenon is common to all modes of transport running over-capacity as Figure 1 illustrates, using the TRB level of service concept. 


\begin{tabular}{|c|c|c|c|c|}
\hline \multirow{2}{*}{$\begin{array}{l}\text { Mode } \\
\text { Inter-urban } \\
\text { roads }\end{array}$} & \multicolumn{2}{|l|}{ Europe } & \multicolumn{2}{|l|}{ US } \\
\hline & $\begin{array}{l}\text { Mainly Randstad and Ruhr } \\
\text { areas and urban access }\end{array}$ & $C *$ & $\begin{array}{l}\text { Highway intersections and } \\
\text { around agglomerations }\end{array}$ & $B \times$ \\
\hline Urban roads & $\begin{array}{l}\text { Severe congestion in some } \\
\text { cities, no general problem }\end{array}$ & $C *$ & $\begin{array}{l}\text { Steadily increasing but not } \\
\text { perceived as major problem }\end{array}$ & D $x$ \\
\hline Rail & $\begin{array}{l}\text { Only at port hinterland } \\
\text { lines; technical standards }\end{array}$ & $\mathrm{B} \rightarrow$ & $\begin{array}{l}\text { Considerable lag in grade- } \\
\text { separated facilities in major } \\
\text { lines }\end{array}$ & D $x$ \\
\hline Aviation & $\begin{array}{l}\text { Problems in major hubs } \\
\text { (London, Paris); airspace }\end{array}$ & $C \&$ & $\begin{array}{l}\text { Constant investments and } \\
\text { still recovery from } 9 / 11\end{array}$ & $B x$ \\
\hline $\begin{array}{l}\text { Waterborne } \\
\text { transport }\end{array}$ & $\begin{array}{l}\text { Only port hinterland trans- } \\
\text { port (Rotterdam) }\end{array}$ & $B \rightarrow$ & $\begin{array}{l}\text { Port capacity and conges- } \\
\text { tion on hinterland routes }\end{array}$ & D $x$ \\
\hline
\end{tabular}

Legend: $A$ (= congestion-free) to $E$ (totally congested): Current situation. wy (fastly declining quality) to ir (clearly improving conditions): expected future transport system quality

Figure 4: Direct comparison between EU and USA congestion - Summary of findings [24].

Road congestion is particularly prevalent in bigger agglomerations and their access routes. As more and more people live within cities and motorization rates increase at a global level, the pressures on existing infrastructures are burdensome and affect all, imposing delays and air pollution on citizens and businesses alike. Incentives to the expansion of road supply usually results in more congestion, as improved travel costs call for a latent demand that would otherwise not take place - aka the vicious circle of congestion.

Estimates range between 60 to over 100 megacities (with populations over 10 million) by 2050 globally (with China alone hosting 50) [25], with significant implications in terms of mobility and congestion Some mega recurrent congested situations today in cities like São Paulo, BR, which saw a record breaking $562 \mathrm{~km}$ of queues on its network on a Friday afternoon in June 2012, or Beijing, where the local Traffic Management Bureau announced over $90 \%$ of roads saturated or super-saturated in the morning and evening peak hours, give us a glimpse of what the future may hold for these conurbations.

The quest for congestion-free transportation systems is not practicable or economically viable as ultimately congestion reflects system demand and is an evidence of social and economic vitality. Yet, lack of proper system capacity planning and mobility-related policies addressing demand management, given future demand pressures on current infrastructures, poses a massive threat on future regional economic efficiency and competitiveness, imposing high costs on businesses, workers, and quality of life of present and future generations.

Strategies to relieve congestion rely mostly on policies and regulatory mechanisms addressing pricing, intelligent transportation systems and vehicle technology, parking supply management, car-pooling, HOV lanes, ownership or traffic restrictions. Congestion and air pollution places increasing stress upon public services to provide a convenient, affordable and safe transport supply to the masses, creating a window of opportunity to providers and operators of mass transit systems worldwide. 


\section{Conclusion}

The world is increasingly aware of the challenges it faces, such as an old-age society and its intrinsic requirements, meeting the energy needs of the world in 2050 and feeding 9 billion people. Just by 2030, the world will need between $40 \%$ and 50\% more water, food and energy [26]. In a World Wildlife Fund study, the total investment in urban infrastructures and operations up to 2050 will exceed a staggering \$US350 trillion, requiring significant innovation in terms of funding and financing schemes to accomplish this huge undertaking.

By 2050, over three-quarters of the population will be living in cities, with the most dynamic growth to be felt in thousands of smaller towns that will rapidly develop into cities.

Table 1 presents the expected evolution of global demand for transportation in the medium term, according to various foresight studies on the transportation field.

Table 1: Expected evolution of transport demand by mode by different sources (index $100=2010$ ).

\begin{tabular}{cccc}
\hline & & 2030 & 2050 \\
\hline \multirow{2}{*}{ Aviation } & Pax & $160-220$ & $240-360$ \\
& Freight & $237-253$ & - \\
\hline \multirow{2}{*}{ Waterbourne } & Pax & - & - \\
& Freight & $146-188$ & $227-370$ \\
\hline \multirow{2}{*}{ Rail } & Pax & - & $219-286$ \\
& Freight & - & $180-240$ \\
\hline \multirow{2}{*}{ Road } & Private Car & & Nore \\
& Bus\&Coach & - & Noulle \\
& Freight & &
\end{tabular}

These values represent a high level view on what current foresight studies indicate for future transportation demand growth. This range of figures sets out clearly that current expectations for demand growth are of a very significant increase over the next 3 to 4 decades, to which transportation planners and industry players must envisage the best strategies to cope.

\section{References}

[1] Thompson, Louis. A vision for Railways 2050. OECD/ITF, 2010.

[2] DESA - UN. World Population Prospects - the 2012 Revision. New York: United Nations - Department of Economic and Social Affairs - Population Division, 2013.

[3] UNFPA. Ageing in the twenty-first century: A Celebration and a Challenge. New York: United Nations Population Fund, 2012. 
[4] Dobbs, Richard, Jaana Remes, James Manyika, Charles Roxburgh, Sven Smit, and Fabian Schaer. Urban world: cities and the rise of consuming class. Mckinsey Global Institute, 2012.

[5] Lloyd's Register. Global maritime trends 2030. Glasgow: Lloyd's Register Group Limited, QinetiQ, University of Strathclyde and Marine Strategies International Limited, 2013.

[6] OICA. "2013 PRODUCTION STATISTICS.” Organisation Internationale des Constructeurs d'Automobiles. www.oica.net (accessed March 28, 2014).

[7] Frost \& Sullivan. "Urban Mobility - What can we learn from China." Slideshare. 21 January 2014.

http://www.slideshare.net/FrostandSullivan/urban-mobility-what-can-welearn-from-china.

[8] Fray, Bruno S. Happiness - A Revolution in Economics. Cambridge MA: The MIT Press, 2008.

[9] UNFPA. "State of world population." 2007.

[10] EIU. China's urban dreams, and the regional reality. Economist intelligence Unit, 2014.

[11] "The Trend Compendium 2030." Roland Berger website. http://www.rolandberger.com/gallery/trend-compendium/tc2030/ (accessed February 2013).

[12] UNFPA. State of World Population 2007: Unleashing the Potential of Urban Growth. New York: United Nations Population Fund, 2007.

[13] WEF. Global Risks 2014. Geneva: World Economic Forum, 2014.

[14] EEA. The European Environment - State and Outlook 2010: Assessment of Global Megatrends. Copenhagen: European Environment Agency, 2011b.

[15] EC. Roadmap to a Single European Transport Area - Towards a competitive and resource efficient transport system. Brussels: European Commission, 2011.

[16] Gori, Stefano, Marialisa Nigro, and Marco Petrelli. "The impact of land use characteristics for sustainable mobility: the case study of Rome." European Transport Reseach Review, 2012: 153-166.

[17] Brög, Werner, Franz Barta, and Erhard Erl. "Societal megatrends: like it or not, the framework is set." 56th UITP World Congress. 2005.

[18] Huetlin, Thomas. "Car-sharing gears up in German Cities." Spiegel Online, 28 August 2013.

[19] Singh, Sarwant. "Future of personal mobility - life with or without the ownership of cars." Forbes, 23 April 2014.

[20] Zachmann, Georg, et al. The great transformation: decarbonising Europe's energy and transport systems. Brussels, Belgium: Bruegel Brueprint 16, 2012, . Bruegel Brueprint 16, Brussels, Belgium.

[21] Roland Berger. Automotive landscape 2025 - Opportunities and challenges ahead. Roland Berger Strategy Consultants, 2011.

[22] Vergragt, Philip J., and Halina S. Brown. "Sustainable mobility: from technological innovation to societal learning. Journal of Cleaner Production, 15." 2007: 1104-1115. 
[23] UNEP, United Nations Environment Programme. Global Environment Outlook, Environment for the future we want. United Nations, 2012.

[24] IEA, International Energy Agency. "Key World Energy Statistics." 2012.

[25] COMPETE. "COMPETE Final Report - Analysis of the contribution of transport policies to the competitiveness." 2006.

[26] World Energy Council. "Global Transport Scenarios 2050.” London, 2011.

[27] Shell. New lens Scenarios - A shift in perspective for a world in transition. Foresight Study, Shell International BV, 2013. 